Tropical Journal of Pharmaceutical Research September 2018; 17 (9): 2093-2099

ISSN: $1596-5996$ (print); 1596-9827 (electronic)

(C) Pharmacotherapy Group, Faculty of Pharmacy, University of Benin, Benin City, 300001 Nigeria.

Original Research Article

http://dx.doi.org/10.4314/tjpr.v17i9.29

\title{
Combination of thymosin $\alpha 1$ with conventional therapy improves APC and IL-1R1 levels in children with severe pneumonia
}

\author{
Li Shuangquan ${ }^{1}$, Wang Jianzhong ${ }^{1}$, Liu Hongfeng ${ }^{2}$, Li Gang ${ }^{1}$, Shen Wenli ${ }^{1}$, Gao \\ Caiyun ${ }^{1}$, Liu Yuanhui ${ }^{1}$, Wu Chunqing ${ }^{1}$, Zhao Xuelian ${ }^{3}$, Han Zhonghou ${ }^{4 *}$ \\ ${ }^{1}$ Department of Paediatrics, ${ }^{2}$ Department of Anesthesiology, ${ }^{3}$ Department of Obstetrics, ${ }^{4}$ Department of Hospital Management, \\ Qinhuangdao Maternity and Child Health Hospital, Hebei 066000, China
}

*For correspondence: Email: vf1215@163.com; Tel: +86-0335-3852145

Sent for review: 19 May 2018

Revised accepted: 26 August 2018

\begin{abstract}
Purpose: To investigate the effect of a combination of thymosin a 1 with conventional regimen on APC and IL-1R1 levels in children with severe pneumonia, and to provide a reference for its clinical treatment.

Methods: A total of 96 children with severe pneumonia over a period of two years were divided into control and observation groups (48 cases per group) by random number table method. The patients consisted of 46 males and 50 females within the age range of $0.1-6$ years (mean age $=3.0 \pm 1.2$ years), and mean duration of $13.4 \pm 2.2$ days). Their acute physiology and chronic health evaluation II (APACHE II) was $20.3 \pm 3.2$ points. Patients in the control group were placed on conventional treatment programs, while those in the observation group, in addition to the conventional treatments, received thymosin $\alpha 1$ (subcutaneous injection of thymosin $\alpha 1$ at a dose of $1.5 \mathrm{mg}$ per injection) twice daily for the first 3 days, then once daily until the 7th day, after which the adverse reactions were observed and treated. Pulmonary function indices, and levels of APC, and IL-1R1 were also determined in the patients' sera before and after the treatment regime.

Results: The clinical efficacy of the observation group was significantly better $(p<0.05)$ than that of control. There were no significant differences $(p>0.05)$ in the indices of pulmonary function (maximal inspiratory and expiratory pressure, and peak expiratory flow) between the two groups before treatment. However, after treatment they were significantly higher $(p<0.05)$ in the observation group than in control. There were no significant differences $(p>0.05)$ in APC and IL-1R1 levels between the two groups before treatment, but after treatment, while the level of APC in the observation group was significantly increased ( $p<0.05)$, the IL-1R1 level was significantly decreased $(p<0.05)$, when compared to the control group. Both groups showed no obvious adverse reactions during the treatment regime.

Conclusion: Combining thymosin $\alpha 1$ with routine treatment in the management of children with severe pneumonia can significantly alleviate the symptoms of patients, greatly stimulate recovery of pulmonary function, improve APC and IL-1R1 levels, and prevent inflammation.
\end{abstract}

Keywords: Pneumonia, Thymosin a1, Routine treatment, Inflammatory factors, Pulmonary function

This is an Open Access article that uses a funding model which does not charge readers or their institutions for access and distributed under the terms of the Creative Commons Attribution License (http://creativecommons.org/licenses/by/4.0) and the Budapest Open Access Initiative (http://www.budapestopenaccessinitiative.org/read), which permit unrestricted use, distribution, and reproduction in any medium, provided the original work is properly credited.

Tropical Journal of Pharmaceutical Research is indexed by Science Citation Index (SciSearch), Scopus, International Pharmaceutical Abstract, Chemical Abstracts, Embase, Index Copernicus, EBSCO, African Index Medicus, JournalSeek, Journal Citation Reports/Science Edition, Directory of Open Access Journals (DOAJ), African Journal Online, Bioline International, Open-J-Gate and Pharmacy Abstracts 


\section{INTRODUCTION}

Pneumonia is a common disease that endangers human health, and its death rate ranks first on the list of infectious diseases, accounting for onefifth of all deaths caused by diseases worldwide [1]. Severe pneumonia, a category of pneumonia, is characterized by common respiratory symptoms, failure of respiratory organs and other tissues, it and results in high mortality in children. It has become an important clinical disease with obvious epidemiology and outcome characteristics, which requires an initial antibiotic therapy followed by comprehensive treatment in an intensive care unit (ICU) [2].

Children with severe pneumonia experience immune dysfunction (abnormal immune mechanism) which leads to the activation of a large number of inflammatory cells and factors. Therefore, routine treatment is usually performed using immunosuppressive agents. Thymosin $\alpha 1$ is an immune agonist that regulates the proliferation and differentiation of immune cells, inhibits the release of inflammatory factors and relieves the clinical symptoms of pneumonia in children [3]. Activated protein C (APC) is an antithrombotic protease (possesses an anticoagulation effect), which is directly involved in the occurrence and development of pneumonia [4]. Interleukin-1R1 (IL-1R1) is an important factor in the regulation of inflammatory response, and its level is usually elevated during such responses [5].

Thymosin $\alpha 1$ and IL-1R1 can be used as biomarkers to assess the level and severity of pneumonia in children, and proffer treatment. In this study, patients with early postoperative inflammatory small-bowel obstruction (EPISBO) who underwent abdominal surgery were used. The aim of the present study was to investigate the effect of combination of thymosin $\alpha 1$ with conventional regimen on APC and IL-1R1 levels in children with severe pneumonia, and to provide a reference for the clinical treatment.

\section{EXPERIMENTAL}

\section{Materials}

Enzyme-linked immunosorbent assay (ELISA) kits for the detection of IL-1R1 and APC were purchased from Wuhan Huamei Biological Co. Ltd. Thymosin a1 (H20030407) was obtained from Hainan Shuangcheng Pharmaceutical Co. Ltd., while Vmax lung function measuring instrument was obtained from Senisi Co. Ltd. (USA).
This research was approved by the Ethical Committee of Department of Hospital Management, Qinhuangdao Maternity and Child Health Hospital, Hebei, China (approval no. 2018517) and followed the guidelines of Declaration of Helsinki promulgated in 1964 as amended in 1996 [6].

\section{Patients and general information}

A total of 96 children with severe pneumonia over a period of two years were used for this study, and they consisted of 46 males and 50 females within the age range of $0.1-6$ years (mean age $=3.0 \pm 1.2$ years, and mean duration $=13.4 \pm 2.2$ days). Their acute physiology and chronic health evaluation II (APACHE II) was $20.3 \pm 3.2$ points. The patients were divided into control and observation groups (48 cases per group) by random number table method. Patients in the control group consisted of 22 males and 26 females (mean age $=2.9 \pm 1.8$ years, and mean duration = $13.5 \pm 2.1 \mathrm{~d}$ ), and the APACHE II score was $20.5 \pm 3.2$ points. The observation group had 24 males and 24 females (mean age $=3.0 \pm 1.1$ years, and mean duration $=13.3 \pm$ 1.9 days), and the APACHE II score was $20.1 \pm$ 2.4 points. There were no significant differences in sex, age and disease status between the two groups. The study was approved by the Ethics Committee of Qinhuangdao Maternity and Child Health Hospital, Hebei, China, and the patients and their family members understood the study protocol and signed written informed consent.

\section{Inclusion and exclusion criteria}

The inclusion criteria were as follows: (1) patients consistent with the diagnostic criteria for severe pneumonia established in 2014 by the American Thoracic Society [6]; (2) patients who needed mechanical ventilation; (3) patients with daily urine volume < $400 \mathrm{ml}$; (4) patients whose lung lesions increased to more than $50 \%$ within $48 \mathrm{~h}$ after admission; and (5) patients whose family members were informed and signed written informed consent.

The exclusion criteria were as follows: (1) children with other infections; (2) children with severe liver and kidney dysfunction, autoimmune diseases, nervous system diseases, or other diseases; and (3) children who did not cooperate with the study protocol.

\section{Treatment}

Patients in the control group were placed on conventional treatment programs such as antibacterial, cough, electrolyte balance, 
nutritional support and oxygen therapies, while those in the observation group in addition to the conventional treatment received thymosin $\alpha 1$ treatment (subcutaneous injection of thymosin $\alpha 1$ at a dose of $1.5 \mathrm{mg}$ per injection) twice daily for the first 3 days, then once daily until the $7^{\text {th }}$ day, after which the adverse reactions were observed and treated.

\section{Evaluation of clinical efficacy}

The clinical efficacy of the patients was evaluated after one week of treatment as follows: (1) Cured: clinical symptoms of children disappeared completely, while chest X-ray examination was normal; (2) Effective: cases where clinical symptoms of children had some changes, and the inflammatory response was reduced and chest $X$ - ray examination was normal; and (3) Ineffective: children with no significant changes or increase in their clinical symptoms. The overall effectiveness/efficacy (OE) was calculated according to equation 1 where $C$ is the number of cured cases, $E$ is the number of effective cases and $T$ is the total number of cases.

$\mathrm{OE}=(\mathrm{C}+\mathrm{E}) / \mathrm{T} \times 100 \%$

\section{Determination of serum IL-1R1 and APC levels}

Serum IL-1R1 and APC levels were measured before treatment, and 1 week after treatment. Fasting venous blood $(5 \mathrm{ml})$ was collected from each group of patients in the morning and centrifuged at $3000 \mathrm{rpm}$ for $10 \mathrm{~min}$, after which the samples were preserved in $-80{ }^{\circ} \mathrm{C}$, in strict compliance with the of ELISA kit manufacturer's instructions.

\section{Assessment of pulmonary function index}

The pulmonary function index, maximal midexpiratory flow curve (MMF), maximal inspiratory pressure $\left(\mathrm{PI}_{\max }\right)$, maximal expiratory pressure $\left(P E_{\max }\right)$, and peak expiratory flow (PEF) of patients were monitored using Vmax lung function measuring instrument before and 1 week after treatment.

\section{Adverse reaction}

After 2 months of treatment, adverse reactions were observed and documented.

\section{Statistical analysis}

Data are expressed as mean $\pm S D$, and were analyzed using SPSS (19.0). Differences between the two groups were compared using paired $t$-test and $x^{2}$ test. Values of $p<0.05$ were considered statistically significant.

\section{RESULTS}

Subcutaneous injection of thymosin $\alpha 1$ (for immune regulation) followed by a combination of ceftazidime with azithromycin (treatment for inflammation), after 1 month, to a 1 year old (male) patient with severe mycoplasma pneumonia complicated with bacterial infection led to an obvious improvement in the chest radiograph (Figure 1 ). With a 3 years old (male) patient, there was obvious improvement after 12 days treatment with subcutaneous injection of thymosin $\alpha 1$ and cefoperazone sulbactam as shown in Figure 2. Similarly, thymosin $\alpha 1$ was administered with azithromycin or ceftazidine and there was improvement within $6-9$ days as shown in Figures 3 5

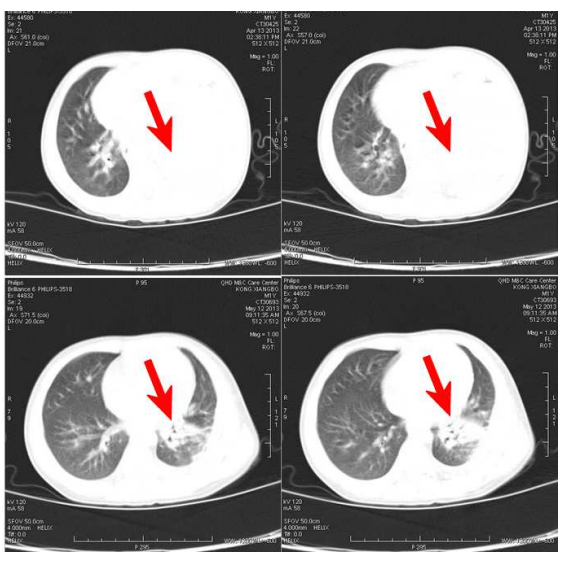

Figure 1: Chest radiograph of 1 year old (male) with severe mycoplasma pneumonia complicated with bacterial infection treated with subcutaneous injection of thymosin $\alpha 1$ (for immune regulation), followed by a combination of ceftazidime with azithromycin (treatment for inflammation) for 1 month.

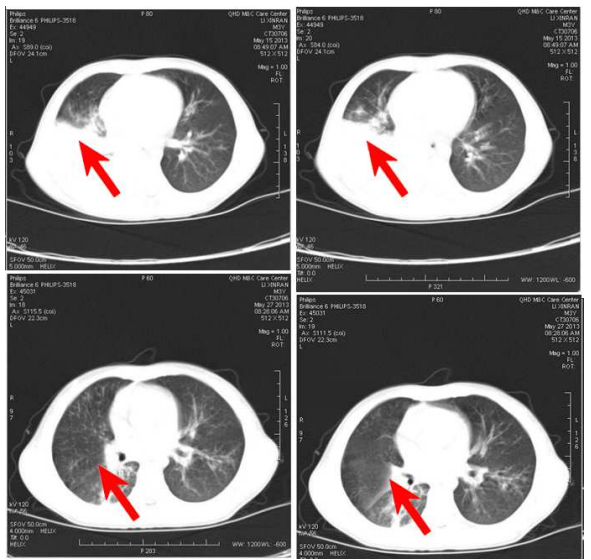

Figure 2: Chest radiograph of a 3 years old (male) patient after treatment with subcutaneous injection of thymosin $\alpha 1$ and cefoperazone sulbactam 


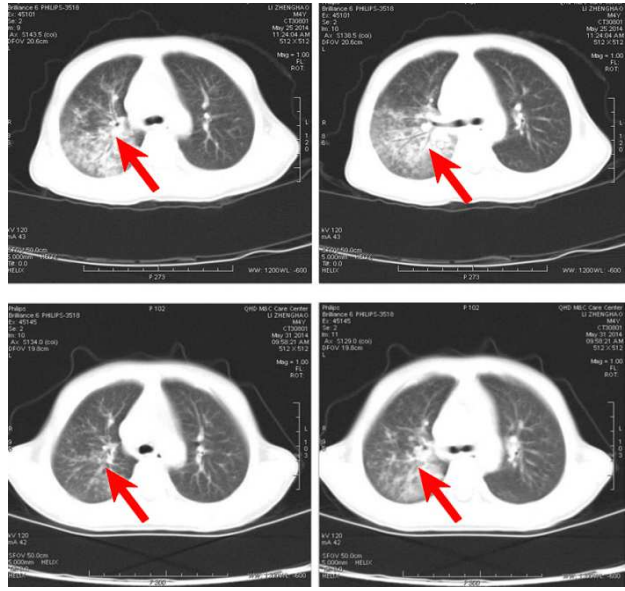

Figure 3: Chest radiograph of patient in assessment 3. The patient was 4 years old, with mycoplasma pneumonia, and after treatment with subcutaneous injection of thymosin $\alpha 1+$ azithromycin, the chest radiograph showed an obvious improvement after 6 days

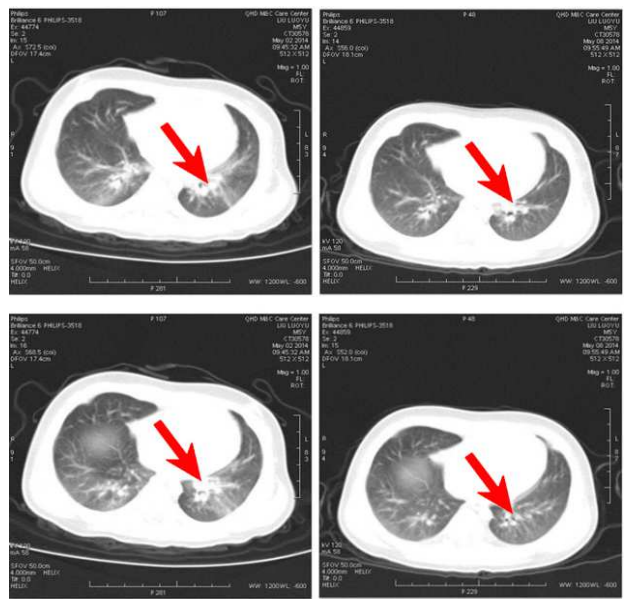

Figure 4: Chest radiograph of patient in assessment 4. The patient was 5 years old, with mycoplasma pneumonia, and after treatment with subcutaneous injection of thymosin $\alpha 1+$ azithromycin, the chest radiograph showed an obvious improvement after 6 days.

\section{Clinical efficacy}

All the patients successfully completed their treatments. In the control group, 17 cases were cured, 18 cases were effective, 13 were ineffective, and the overall effectiveness was $72.90 \%$. In the observation group, 22 cases were cured, 23 cases were effective, 3 were

Table 1: Clinical effects observed in the two groups ineffective, and the overall effectiveness was $93.70 \%$. The clinical efficacy of the observation group was significantly better $(p<0.05)$ than that of the control, as shown in Table 1.
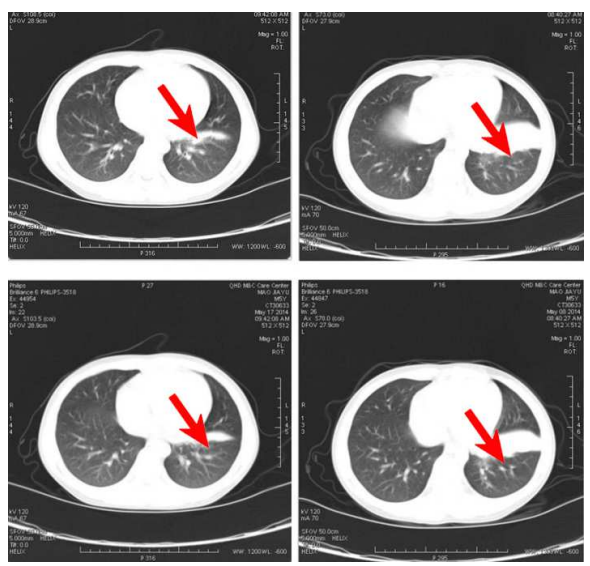

Figure 5: Chest radiograph of patient in assessment 5. The patient was 5 years old, and had bacterial pneumonia. After treatment with subcutaneous injection of thymosin $\alpha 1$ + ceftazidime, the chest radiograph showed an obvious improvement after 9 days.

\section{Indicators of pulmonary function}

There were no significant differences $(p>0.05)$ in $\mathrm{PI}_{\max }, \mathrm{PE}_{\max }$ and $\mathrm{PEF}$ between the two groups before treatment, but after treatment, the indices were significantly higher $(p<0.05)$ in the observation group, when compared to control (Tables 2 and 3).

\section{APC and IL-1R1 levels}

There were no significant differences $(p>0.05)$ in APC and IL-1R1 levels between the two groups before treatment, but after treatment, while the level of APC in the observation group was significantly increased $(p<0.05)$, the level of IL-1R1 was significantly decreased $(p<0.05)$, when compared to the control group (Table 4).

\section{Adverse reactions}

There was no death in both groups, and no significant adverse effects were associated with the treatment.

\begin{tabular}{lccccc}
\hline Group & $\mathbf{N}$ & Cured & Effective & Ineffective & $\begin{array}{l}\text { Overall effectiveness } \\
(\%)\end{array}$ \\
\hline Control group & 48 & 17 & 18 & 13 & 72.9 \\
Observation group & 48 & 22 & 23 & 3 & 93.7 \\
$U / X^{2}$ & & $U=4.56$ & & & $X^{2}=12.3$ \\
$P$ & & $P<0.01$ & & $p<0.01$ \\
\hline
\end{tabular}


Table 2: Pulmonary function indices (MMF and PEF) for the two groups

\begin{tabular}{|c|c|c|c|c|c|c|c|c|c|}
\hline \multirow[b]{2}{*}{ Group } & \multirow[b]{2}{*}{$\mathbf{N}$} & \multicolumn{2}{|c|}{ MMF (L/s) } & \multirow[b]{2}{*}{$t$} & \multirow[b]{2}{*}{$P$} & \multicolumn{2}{|c|}{ PEF(L/s) } & \multirow[b]{2}{*}{$t$} & \multirow[b]{2}{*}{$p$} \\
\hline & & $\begin{array}{c}\text { Before } \\
\text { treatment }\end{array}$ & $\begin{array}{l}\text { After } \\
\text { treatment }\end{array}$ & & & $\begin{array}{l}\text { Before } \\
\text { treatment }\end{array}$ & $\begin{array}{l}\text { After } \\
\text { treatment }\end{array}$ & & \\
\hline Control group & 48 & $\begin{array}{l}0.74 \pm \\
0.21\end{array}$ & $\begin{array}{l}1.44 \pm \\
0.69\end{array}$ & 6.96 & 0.00 & $1.14 \pm 0.11$ & $1.44 \pm 0.32$ & 4.65 & 0.00 \\
\hline Observation group & 48 & $\begin{array}{l}0.73 \pm \\
0.25\end{array}$ & $\begin{array}{l}1.75 \pm \\
0.72\end{array}$ & 8.58 & 0.00 & $1.13 \pm 0.15$ & $2.45 \pm 0.26$ & 5.32 & 0.00 \\
\hline$t$ & & 0.72 & 4.12 & & & 0.76 & 6.54 & & \\
\hline$P$ & & 0.63 & 0.00 & & & 0.67 & 0.00 & & \\
\hline
\end{tabular}

Table 3: Pulmonary function indices (PImax, PEmax) for the two groups

\begin{tabular}{|c|c|c|c|c|c|c|c|c|c|}
\hline \multirow[t]{2}{*}{ Group } & \multirow[b]{2}{*}{$\mathrm{N}$} & \multicolumn{2}{|c|}{$\mathrm{PI}_{\max }(\%)$} & \multirow{2}{*}{$t$} & \multirow[b]{2}{*}{$p$} & \multicolumn{2}{|c|}{$\mathrm{PE}_{\max }(\%)$} & \multirow[b]{2}{*}{$t$} & \multirow[b]{2}{*}{$p$} \\
\hline & & $\begin{array}{c}\text { Before } \\
\text { treatment }\end{array}$ & $\begin{array}{c}\text { After } \\
\text { treatment }\end{array}$ & & & $\begin{array}{c}\text { Before } \\
\text { treatment }\end{array}$ & $\begin{array}{c}\text { After } \\
\text { treatment }\end{array}$ & & \\
\hline Control group & 48 & $\begin{array}{c}61.14 \pm \\
10.11\end{array}$ & $\begin{array}{c}72.44 \pm \\
7.02\end{array}$ & 8.53 & 0.00 & $\begin{array}{c}35.14 \pm \\
7.11\end{array}$ & $\begin{array}{c}39.44 \pm \\
8.32\end{array}$ & 10.96 & 0.00 \\
\hline $\begin{array}{l}\text { Observation } \\
\text { group }\end{array}$ & 48 & $\begin{array}{c}61.53 \pm \\
10.15\end{array}$ & $\begin{array}{c}82.45 \pm \\
8.72\end{array}$ & 10.75 & 0.00 & $\begin{array}{l}35.53 \pm \\
7.15\end{array}$ & $\begin{array}{l}48.45 \pm \\
8.76\end{array}$ & 12.96 & 0.00 \\
\hline$t$ & & 0.89 & 15.32 & & & 0.78 & 8.66 & & \\
\hline$P$ & & 0.48 & 0.00 & & & 0.87 & 0.00 & & \\
\hline
\end{tabular}

Table 4: Levels of APC and IL-1R1 in the two groups

\begin{tabular}{|c|c|c|c|c|c|c|c|c|c|}
\hline \multirow[b]{2}{*}{ Index } & \multirow[b]{2}{*}{$\mathbf{N}$} & \multicolumn{2}{|c|}{ APC (pg/ml) } & \multirow[b]{2}{*}{$t$} & \multirow[b]{2}{*}{$p$} & \multicolumn{2}{|c|}{ IL-1R1 (ng/ml) } & \multirow[b]{2}{*}{$t$} & \multirow[b]{2}{*}{$p$} \\
\hline & & $\begin{array}{c}\text { Before } \\
\text { treatment }\end{array}$ & $\begin{array}{c}\text { After } \\
\text { treatment }\end{array}$ & & & $\begin{array}{c}\text { Before } \\
\text { treatment }\end{array}$ & $\begin{array}{c}\text { After } \\
\text { treatment }\end{array}$ & & \\
\hline Control group & 48 & $\begin{array}{c}102.65 \pm \\
60.67\end{array}$ & $\begin{array}{c}262.56 \pm \\
71.67\end{array}$ & $\begin{array}{c}21.1 \\
06\end{array}$ & 0.03 & $\begin{array}{c}0.78 \pm \\
0.16\end{array}$ & $\begin{array}{c}0.43 \pm \\
0.12\end{array}$ & $\begin{array}{c}6.2 \\
0\end{array}$ & 0.00 \\
\hline $\begin{array}{c}\text { Observation } \\
\text { group } \\
t \\
p\end{array}$ & 48 & $\begin{array}{c}100.09 \pm \\
62.88 \\
1.21 \\
0.23\end{array}$ & $\begin{array}{c}435.75 \pm \\
72.36 \\
16.42 \\
0.00\end{array}$ & $\begin{array}{c}24.7 \\
7\end{array}$ & 0.00 & $\begin{array}{l}0.77 \pm \\
0.17 \\
1.92 \\
0.06\end{array}$ & $\begin{array}{l}0.23 \pm \\
0.10 \\
6.32 \\
0.00\end{array}$ & $\begin{array}{c}7.6 \\
9\end{array}$ & 0.00 \\
\hline
\end{tabular}

\section{DISCUSSION}

Pediatric pneumonia is one of the major causes of death of young children in China, and these children usually suffer from dysfunctions of some of their organs and tissues [7]. Studies have shown that severe pneumonia in children is also accompanied by septic shock, heart failure, immune system disorders, immune dysfunction and other symptoms which can lead to the release of large number of inflammatory factors and activation of inflammatory cells, and induction of systemic inflammatory responses [8]. Therefore, in addition to water and electrolyte remediation which are conventional methods of treatment, the clinical management of children with this disease also requires treatment of the inflammatory response. Thymosin $\alpha 1$, an immune stimulant, can regulate the normal function of immune cells, improve CD3+ and CD4+ lymphocyte counts, inhibit IL-6 and other inflammatory factors, alleviate the local inflammatory response, and improve lung function [9].

The results of the present study shows that clinical efficacy of the observation group was significantly better than that of control, while the two groups of patients had no significant drugrelated adverse reactions. These results appear to suggest that the combination of thymosin $\alpha 1$ with conventional treatment regimen may significantly improve patients' adverse symptoms. These findings are in agreement with those of Gou et al [10], who reported that thymosin $\alpha 1$ had a significant clinical effect on elderly patients with severe pneumonia. Clinical symptoms observed in children can be improved by routine strategies such as antibacterial, cough, water and electrolyte balance treatment; nutritional support, oxygen therapy, and use of thrombolytic peptide. Thrombolytic peptide is a biologically active molecule which can stimulate T-cells to secrete a variety of cytokines, promote the expressions of antigen and cytokine 
receptors on the surface of immune cells, and regulate the recovery of immune function in patients. In this study, thymosin $\alpha 1$ was welltolerated, and the patients had no obvious adverse reactions. Therefore, the children recovered significantly from the clinical symptoms, and there was a favorable prognosis [11]. After treatment, $\mathrm{PI}_{\max }, \mathrm{PE}_{\max }$, and PEF of the observation group were significantly higher than those of control, which showed that the combination of thymosin $\alpha 1$ with conventional therapy appeared to have positive effect on lung symptoms and facilitated the recovering of respiratory function.

Key transduction factors (MyD88 in IL-1R1 and Toll / IL-1R signaling pathway) are important in mediating inflammatory responses, and MyD88 activates the response using elastase in combination with IL-1 $1 \beta$. The levels of IL-1 and IL$1 \mathrm{R} 1$ are positively correlated and are higher than normal in the course of an inflammatory reaction. Therefore, IL-1R1 can be used as a serum marker to assess the degree of inflammatory response in children [12]. In the present study, after treatment, the IL-1R1 level in the observation group was significantly lower than that in control, an indication that the local inflammatory response possibly got a favorable environment, and so IL - 1R1 level returned to normal. The reason may be that thymosin $\alpha 1$ induced thymocyte proliferation and differentiation, promoted the maturation of $\mathrm{T}$ lymphocytes, and significantly increased the level of interleukin-7 (IL-7) in the blood. The expression of thymopoietin is stimulated by IL-7, so thymosin $\alpha 1$ and IL-1R1 can together resist inflammation [12].

The anti-inflammatory, fibrinolytic and antiapoptotic effects of APC enable it to protect blood vessels and organs [13]. Its antiinflammatory effect is exerted through the inhibition of monocytes to produce tumor necrosis factor $\alpha$ (TNF- $\alpha$ ) and IL-1, thus inhibiting the binding of neutrophils to endothelial cells [14]. In this study, the level of APC in the observation group before treatment was significantly lower than the normal level. However, after treatment, it increased more than that of the control group, an indication that thymosin $\alpha 1$ may significantly increase the level of APC and alleviate the inflammatory reaction.

\section{Study limitations}

The major shortcoming in this study is the use of a small sample size. In subsequent studies the sample size should be expanded and should include patients from other races/populations.

\section{CONCLUSION}

Combination of thymosin $\alpha 1$ with routine treatment in the management of children with severe pneumonia can significantly alleviate the symptoms of patients, and greatly stimulate recovery of pulmonary function. It can also improve APC and IL-1R1 levels, and largely prevents inflammation.

\section{DECLARATIONS}

\section{Conflict of Interest}

No conflict of interest associated with this work.

\section{Contribution of Authors}

We declare that this work was done by the author(s) named in this article and all liabilities pertaining to claims relating to the content of this article will be borne by the authors. All authors read and approved the manuscript for publication. Han Zhonghou conceived and designed the study, Li Shuangquan, Han Zhonghou, Wang Jianzhong, Liu Hongfeng, Li Gang, Shen Wenli, Gao Caiyun, Liu Yuanhui, Wu Chunqing and Zhao Xuelian collected and analysed the data. Li Shuangquan wrote the manuscript.

\section{REFERENCES}

1. Wang $Q$, Zhu $X$, Tang Z. A dead case of severe community-acquired pneumonia caused by highly pathogenic Klebsiella pneumoniae. Zhonghua Wei Zhong Bing Ji Jiu Yi Xue 2017; 29(1): 84-88.

2. Shi Z, Qin Y, Zhu Y, Pan X, Zhou X, Tan Y, Liu Y. Effect of broncho-alveolar lavage with fiber-optic bronchoscopy combined with vibration sputum drainage on mechanically ventilated patients with severe pneumonia: a prospective randomized controlled trial in 286 patients. Zhonghua Wei Zhong Bing Ji Jiu Yi Xue 2017; 29(1): 66-70.

3. King R, Tuthill C. Immune modulation with thymosin alpha 1 treatment. Vitam Horm 2016; 102(23): 151-178.

4. Wilts IT, Hutten BA, Meijers JC, Spek CA, Buller HR, Kamphuisen PW. Association between protein $C$ levels and mortality in patients with advanced prostate, lung and pancreatic cancer. Thromb Res 2017; 154: 1-6.

5. Morine MJ, Toomey S, McGillicuddy FC, Reynolds CM, Power KA, Browne JA, Loscher C, Mills KH, Roche HM. Network analysis of adipose tissue gene expression highlights altered metabolic and regulatory transcriptomic activity in high-fat-diet-fed $|L-1 R|$ knockout mice. J Nutr Biochem 2013; 24(5): 788-795.

6. World Health Organization. Declaration of Helsinki. $\mathrm{Br}$ Med J 1996; 313(7070): 1448-1449.

Trop J Pharm Res, October 2018; 17(10):2098 
7. Xiao $B H$, Wang $M$, Hu XL, Li JF, Wang FF, Sun JX. Antibiotic de-escalation principle in elderly patients with chronic obstructive pulmonary disease complicated with severe pneumonia. Exp Ther Med 2017; 13(4): 14851489.

8. Yi H, Xie CM. Clinical aspects and prognostic factors of severe pneumonia. Chin J Nosocomiol 2008; 10(1): 5658.

9. $X U D M, D i X Z$. Mechanism and research progress of thymosin alpha_1. Med J Chin People's Health 2014; 3(2): 79-82.

10. Gou J. Effects of thymosin alpha 1 on cellular immune function and inflammatory markers in patients with severe pneumonia. J Clin Med Pract 2015; 18(19): 162163.
11. Li WY, Lu HM, Guo Q, Hu WM, Zhang ZD. Effects of thymosin $\alpha 1$ on immune effector molecules of mouse. $J$ Sichuan University 2014; 21(3): 400-404.

12. Knop J, Martin MU. Effects of IL-1 receptor-associated kinase (IRAK) expression on IL-1 signaling are independent of its kinase activity. FEBS Lett 1999; 448(1): 81-85.

13. Tian HZ, Hu CP, Cheng JS. Effect of thymosin $\alpha 1$ on tumor necrosis factor and interleukin-6 in children with severe pneumonia. Clin Med J 2015; 12(1): 38-41.

14. Lin $C$, Vonder-Thüsen J, Isermann $B$, Weiler $H$, van der Poll T. High endogenous activated protein $C$ levels attenuates bleomycin-induced pulmonary fibrosis. J Cell Mol Med 2016; 20(11): 2029-2035. 